\title{
Atividade biológica do extrato hidroalcoólico de Bauhinia forficata Link sobre Herpetomonas samuelpessoai (Galvão.) Roitman
}

\author{
PEREIRA, A.C.S. ${ }^{1}$ RIBEIRO, G.E. ${ }^{2}$; SOUZA, L.C.R. ${ }^{1}$; RUFINO, L.R.A. ${ }^{1}$; CABRAL, I.S.R. ${ }^{2}$; BORIOLLO, M.F.G. ${ }^{1 ;}$ \\ NOGUEIRA,D.A.'; OLIVEIRA, N.M.S.'; FIORINI, J.E.'*. \\ Univesidade José do Rosário Vellano - UNIFENAS, Laboratório de Biologia e Fisiologia de Microrganismos \\ Rodovia MG 179, Km 0, CEP: 37130-000, Alfenas, MG, Brasil. *microrganismo@unifenas.br; ${ }^{*}$ Univerversidade \\ Federal de Alfenas, UNIFAL-MG, Laboratório de Microbiologia e Imunologia Básica, Rua Gabriel Monteiro da \\ Silva, 700, Centro, CEP: 37130-000, Alfenas, MG, Brasil.
}

\begin{abstract}
RESUMO: Inúmeros esforços têm sido dirigidos para conferir às plantas seu real papel e valor na terapia. Este estudo teve como objetivo avaliar a atividade antimicrobiana, mutagênica, toxicidade, e os efeitos no crescimento e diferenciação de Herpetomonas samuelpessoai, do extrato hidroalcoólico de Bauhinia forficata. Para avaliar a atividade antimicrobiana foi realizado o teste de difusão em ágar, bem como a determinação das concentrações inibitória (CIM) e microbicida mínimas (CMM). O potencial clastogênico e/ou aneugênico, in vivo, foi avaliado usando o teste do micronúcleo em medula óssea de camundongos Swiss albinus. Foi determinada também a dose letal média $\left(\mathrm{DL}_{50}\right)$. O extrato inibiu o crescimento de oito bactérias, mostrando-se mais ativo para Gram-positivas e não foi eficiente para os fungos, tendo sido ativo nas concentrações de 2000, 1000, 500 e $250 \mathrm{mg} / \mathrm{mL}$ contra os microrganismos testados. Os resultados mostraram que nas concentrações administradas $(500,1000$ e $2000 \mathrm{mg} / \mathrm{Kg})$, não houve aumento estatisticamente significativo de micronúcleos. Não houve ação no crescimento e diferenciação de Herpetomonas samuelpessoai nas concentrações testadas. Com relação a $\mathrm{DL}_{50}$, o extrato não apresentou toxicidade.
\end{abstract}

Palavras-chave: Bauhinia forficata, Herpetomonas samuelpessoai, pata de vaca, antimicrobianos, mutagenicidade.

ABSTRACT: Biologic activity of the hydroalcoholic extract of Bauhinia forficata Link on Herpetomonas samuelpessoai (Galvão.) Roitman. Numerous efforts have been directed to discover the role and the value of plants in therapy. This work aimed to evaluate the antimicrobial activity, mutagenicity, toxicity and effects on growth and differentiation of Herpetomonas samuelpessoai of the hydroalcoholic extract of Bauhinia forficata. To evaluate the antimicrobial activity it was performed the agar diffusion test, minimum inhibitory (MIC) and microbicidal (MMC) concentrations. The in vivo clastogenic and / or aneugênic potential was evaluated using the micronucleus test in mice bone marrow Swiss albinus. It was also determined the median lethal dose $\left(L_{50}\right)$. The extract inhibited the growth of eight bacteria, being more active against Gram-positiveones, and was not active against fungi. The microorganisms tested had MIC concentrations of $2000,1000,500$ and $250 \mathrm{mg} / \mathrm{mL}$. The results showed that the tested concentrations $(500,1000$ and $2000 \mathrm{mg} / \mathrm{kg}$ ) had no statistically significant increasedthe micronucleus. There was no action on the growth and differentiation of Herpetomonas samuelpessoai at the concentrations tested. In respect to the $\mathrm{LD}_{50}$, the extract showed no toxicity.

Key words:Bauhinia forficata, Herpetomonas samuelpessoai, cow's-paw, antimicrobial, mutagenicity.

\section{INTRODUÇÃO}

Algumas espécies do gênero Bauhinia são conhecidas popularmente como "pata-de-vaca", "unha-de-vaca", entre outros nomes e são utilizadas para fins medicinais. Este gênero pertence à família
Leguminosae e abrange cerca de 300 espécies presentes em áreas tropicais do mundo (Lusa e Bona, 2009).

Bauhina forficata é utilizada na medicina

Recebido para publicação em 20/09/2013

Aceito para publicação em 02/04/2014

10.1590/1983-084X/13_093

Rev. Bras. PI. Med., Campinas, v.16, n.3, p.585-592, 2014. 
popular brasileira e se destaca pela sua relevância terapêutica no tratamento do diabetes mellitus (Trojan-Rodrigues et al., 2012). Possui atividades biológicas como hipoglicemiante (Curcio et al., 2012), antioxidante (Khalil et al., 2008; Peroza et al., 2013) e anticoagulante (Oliveira et al., 2005). Esta espécie desperta o interesse para produção de fitoterápicos e se encontra na Relação Nacional de Plantas Medicinais de Interesse ao Sistema Único de Saúde (RENISUS) (Ministério da Saúde, 2009).

Estudos recentes mostram que substâncias presentes em preparações medicinais podem causar efeitos tóxicos, como danos no DNA, devido à sua citotoxicidade, mutagenicidade e propriedades carcinogênicas. A avaliação dos danos causados são de extrema importância para minimizar os riscos destes agentes, principalmente em tratamentos a longo prazo (Sisenando et al., 2009).

O desenvolvimento de novos fármacos requer uma completa investigação da eficácia e segurança da substância-teste. O potencial de risco e benefício deve ser cuidadosamente considerado, de modo que os benefícios de seu uso superem os efeitos colaterais (Varanda, 2006).

Os estudos fitoquímicos e farmacológicos realizados com $B$. forficata sugerem a presença de proantocianidinas, leucoantocianidinas, triterpenos, esteróides, flavonóides, além de açúcares redutores (Marques et al., 2012; Cechinel Filho, 2003). A literatura aponta os flavonóides como responsáveis pela atividade biológica, sendo a kaempferitrina o marcador químico e farmacológico de excelência (De Sousa et al., 2004; Lino et al., 2004).

Apesar da larga utilização da B. forficata na medicina popular, há poucos estudos sobre a atividade antimicrobiana e seus efeitos genotóxicos, tornado-se necessários estudos científicos que comprovem a eficácia ou ações indesejáveis de suas propriedades.

Este trabalho teve como objetivo verificar a atividade antimicrobiana e mutagênica do extrato hidroetanólico da folha de B.forficata. Segundo Mateuca et al. (2006) a frequência de micronúcleos é forte preditivo para o desenvolvimento de câncer. $O$ teste do micronúcleo em medula óssea de roedores in vivo, além de atender às exigências dos órgãos nacionais que regulam os registros farmacológicos e químicos, também segue as recomendações do Gene-Tox Program da Environmental Protection Agency. Ensaios com sistemas eucarióticos envolvendo seu metabolismo podem indicar a capacidade mutagênica de produtos naturais e sintéticos.

\section{MATERIAL E MÉTODOS}

Preparo do material vegetal e extrato bruto

As folhas de Bauhinia forficata foram coletadas, em um único exemplar da planta, em sua parte média, na Universidade José do Rosário Vellano (UNIFENAS) campus de Alfenas, MG no mês de fevereiro/2010. A cidade fica localizada no sul de Minas Gerais cuja região apresenta clima temperado com temperaturas variando entre 21$25^{\circ} \mathrm{C}$ na época da coleta das folhas. Em seguida, lavadas em água corrente e secas em estufas a $35^{\circ} \mathrm{C}$ durante uma semana para eliminação da umidade $e$ estabilização do conteúdo enzimático. Depois, foram trituradas em moinho elétrico para obtenção do pó. A exsicata foi depositada no Herbário da Unifenas, sob o n'BF-468.

Para preparação do extrato hidroalcoólico foram pesados $200 \mathrm{~g}$ das folhas trituradas, previamente lavadas e secas, e suspensas em 800 $\mathrm{mL}$ de etanol $70 \%(\mathrm{v} / \mathrm{v})$, e submetidas à maceração por sete dias. Após, foi realizada a filtração em papel filtro e o extrato obtido foi concentrado em rotoevaporador em temperatura inferior a $40^{\circ} \mathrm{C}$. Em seguida, foi realizada liofilização do extrato.

\section{Avaliação da atividade antimicrobiana}

\section{Microrganismos e preparo do inóculo}

Foram utilizados os microrganismos relacionados na Tabela 1, oriundos do Laboratório de Biologia e Fisiologia de Microrganismos, da Universidade José do Rosário Vellano/ UNIFENAS, rotulados na American Type Culture Collection (ATCC).

As cepas foram repicadas em ágar Mueller Hinton( $\mathrm{pH} 7,2$ ), incubadas a $37^{\circ} \mathrm{C}$, por $24 \mathrm{~h}$. Para o preparo do inóculo, as culturas de cada microrganismo foram transferidas para tubos de ensaio contendo $9 \mathrm{~mL}$ de salina esterilizada de forma a obter-se turbidez correspondente ao tubo 0,5 da Escala de Mc Farland.

\section{Determinação da Concentração Inibitória Mínima (CIM) e Concentração Microbicida Mínima (CMM)}

A concentração inibitória mínima (CIM) (NCCLS, 2003) foi determinada nos extratos que apresentaram atividade inibitória no teste de difusão em ágar. Os testes foram realizados em microplacas de 96 poços. No primeiro poço foi adicionado o extrato com concentração de 2000 $\mathrm{mg} / \mathrm{mL}$, e a partir deste foram preparadas diluições seriadas decrescentes de $2000 \mathrm{mg} / \mathrm{mL}$ a $3,9 \mathrm{mg} / \mathrm{mL}$. Foram inoculados nos poços $10 \mu \mathrm{L}$ da suspensão microbiana com turvação equivalente ao tubo 0,5 da 
Tabela 1. Microrganismos utilizados nos ensaios com Bauhinia forficata.

\begin{tabular}{ll}
\hline Microrganismos & \\
\hline Bactérias Gram-positivas & Bactérias Gram-negativas \\
\hline Bacillus cereus(ATCC 11778) & Enterobacter aerogenes(ATCC 13046) \\
Bacillus subtilis(ATCC 6633) & Escherichia coli (ATCC 8739) \\
Micrococcus luteus(ATCC 9341) & Klebsiella pneumoniae(ATCC 13883) \\
Staphylococcus aureus (ATCC 6538) & Proteus mirabilis(ATCC 25933) \\
Staphylococcus epidermidis(ATCC12226) & Pseudomonas aeruginosa(ATCC 25619) \\
& Salmonella typhimurium(ATCC 14028) \\
Fungos & Protozoário \\
\hline Candida albicans(ATCC 1023-1) & Herpetomonas samuelpessoae (ATCC 30252) \\
Cryptococcus neoformans(ATCC 20509) & \\
Saccharomyces cerevisiae(ATCC 2601) & \\
\hline
\end{tabular}

Escala de Mac Farland. Foi realizado o controle de esterilidade do meio de cultura e de esterilidade dos extratos. As placas foram incubadas a $37^{\circ} \mathrm{C}$, por 24 horas e após este período foi observado presença ou ausência de turvação. Foi considerado CIM a menor concentração que não apresentou turvação.

A CMM foi realizada nas concentrações do extrato que apresentaram inibição para o crescimento bacteriano. Os testes foram realizados em placas de Petri contendo Ágar Mueller Hinton ( $\mathrm{pH} 7,2$ ) e incubadas a $37^{\circ} \mathrm{C}$ por 24 horas.

\section{Teste de difusão em ágar}

Foi utilizado o método de difusão em ágar atualmente recomendado pelo Clinical and Laboratory Standards Institute (CLSI)(NCCLS, 2003), que se baseia originalmente no método descrito por Bauer et al. (1966). Foram preparadas placas de Ágar Mueller-Hinton $(\mathrm{pH} \mathrm{7,2)}$ para bactérias e Ágar Mueller-Hinton com glicose ( $\mathrm{pH}$ $6,0)$ para leveduras.Posteriormente foram feitos poços de $4 \mathrm{~mm}$ de diâmetro na superfície do ágar, com auxílio de um tubo de metal. Foram preparadas suspensões microbianas em soro fisiológico com turvação correspondente ao tubo 0,5 da Escala de Mc Farland. Esta suspensão foi inoculada $(0,1$ $\mathrm{mL}$ ) na superfície do ágar, com auxílio de swab. Foram colocados nos poços os extratos de folhas de Bauhinia forficata concentrados $10 \mathrm{X}$ objetivando diminuir o volume a ser depositado nos poços e de modo a obter as concentrações finais utilizadas nos experimentos. Um controle positivo com solução de clorexidina a $0,12 \%(\mathrm{v} / \mathrm{v})$ foi também utilizado. Este procedimento foi realizado segundo a metodologia descrita por Barkvoll (1998) e Barros \& Fiorini ( 2000) onde os Autores não utilizaram antibióticos comerciais no procedimento. Também foi utilizado um controle negativo com água destilada. As placas foram incubadas a $37^{\circ} \mathrm{C}$, por 24 horas. Após a incubação foi feita a leitura dos halos de inibição do crescimento microbiano.

\section{Crescimento e diferenciação celular de Herpetomonas samuelpessoai}

A diferenciação celular foi realizada em meio de cultivo quimicamente definido $(\mathrm{pH} 6,5)$ (Roitman et al., 1972). Cerca de $10^{6}$ células foram incubadas juntamente com doses crescentes do extrato hidroalcóolico do vegetal, a $28^{\circ} \mathrm{C}$ por 72 horas.

As células foram coletadas por centrifugação e lavadas $2 \mathrm{X}$ em PBS, pH 7,2. Após a lavagem, as células foram ressuspensas no mesmo tampão e realizado um esfregaço fino lâmina de vidro. A lâmina foi deixada secar a temperatura ambiente e, posteriormente, as células foram coradas pelos métodos Panótico e Giemsa e foram observadas em microscopia óptica objetivando estimar os percentuais de formas pro, para e opistomastigota.

O crescimento de $H$. Samuelpessoai foi estimado por contagem das células em câmara de Neubauer com sistemas controle e submetidos ao tratamento com o extrato após incubação em estufas BOD $28^{\circ} \mathrm{C}$, por um período de 72 horas. Os tripanosomatídeos foram fixados em formalina a $10 \%$. Foram considerados os resultados médios obtidos de pelo menos dois experimentos realizados em duplicata.

\section{Dose letal média $\left(\mathrm{DL}_{50}\right)$}

Para determinação da dose letal média $\left(D_{50}\right)$ foram utilizados grupos de camundongos Swiss albinus ( $\mathrm{n}=3$ animais/grupo/sexo), pesando entre 30 e 40 gramas, provenientes do Biotério Central da UNIFENAS, que receberam, por via oral (V.O.), dose única de diferentes concentrações (3, 50,300 e $2000 \mathrm{mg} / \mathrm{Kg}$ ) do extrato hidroalcoólico de Bauhinia forficata, seguindo as normas da 
Organization for EconomicCo-operation and Development (OECD, 1998) para testar toxicidade oral aguda de produtos químicos. O estudo foi aprovado pelo Comitê de Ética em Pesquisa da Universidade José do Rosário Vellano- UNIFENAS, Campus de Alfenas-MG, sob no 02A/2010.

\section{Teste do Micronúcleo}

Para a realização do teste do micronúcleo (Schmid, 1976), foram utilizados camundongos Swiss albinus, adultos jovens, provenientes do Biotério Central da UNIFENAS. Os animais foram divididos em seis grupos ( $\mathrm{n}=6$ por grupo, sendo 3 machos e 3 fêmeas).

O extrato de $B$. forficata foi testado separadamente empregando-se 3 doses (1000; 1500 e $2000 \mathrm{mg} / \mathrm{Kg}$ de peso corporal), selecionadas de acordo com a $\mathrm{DL}_{50}$, e administrados via gavagem $(100 \mu \mathrm{L} / 10 \mathrm{~g}$ de animal). $\mathrm{O}$ grupo controle negativo recebeu $\mathrm{NaCl}$ $(150 \mathrm{mM})$ por gavagem e o controle positivo foi tratado com N-Nitroso-N-ethylurea (ENU) $(50 \mathrm{mg} /$ $\mathrm{Kg}$ - Sigma N8509) de modo intraperitoneal.

Após 24 e 48 horas do término do tratamento, os animais foram eutanasiados por deslocamento cervical. Os fêmures foram removidos, a epífise proximal foi retirada para expor o canal medular e, com o auxílio de uma agulha $13 \times 4.5 \mathrm{~mm}$ e $3 \mathrm{~mL}$ de solução de $\mathrm{NaCl}(150 \mathrm{mM})$, a medula foi retirada, lavando-se o canal medular com solução de $\mathrm{NaCl}$. O material foi transferido para tubos de vidro e centrifugados a $1000 \mathrm{rpm} / 5 \mathrm{~min}$.

Após a centrifugação, descartou-se o sobrenadante, e o sedimento foi ressuspenso com solução de formaldeído $4 \%$ e levemente homogeneizado com o auxílio de uma pipeta Pasteur. Uma gota desta suspensão celular foi colocada em uma lâmina limpa e seca, e depois, realizou-se o esfregaço.

As lâminas foram secas à temperatura ambiente e, após 24 horas, coradas com Leishman eosina-azul de metileno e submetidas à análise microscópica. Em cada lâmina 2000 eritrócitos policromáticos foram analisados.

\section{Análise estatística}

Para os ensaios de ação antimicrobiana foi utilizada estatística descritiva. Os dados obtidos no teste do micronúcleo foram submetidos à análise estatística de variância one-way (ANOVA), em delineamento inteiramente casualizado e esquema fatorial $5 \times 2 \times 2$ (tratamento $\times$ sexo $\times$ tempo), e ao teste de Tukey empregando o software SAS ${ }^{\circledR}$ (versão 8.01).O teste de Scott-Knott foi empregado para os resultados de crescimento e diferenciação celular. Diferenças estatísticas foram fixadas como sendo significativas para $\rho \leq 0,05$.

\section{RESULTADOS E DISCUSSÃO}

A avaliação do potencial antibacteriano do extrato hidroalcoólicode $B$. forficata, demonstrou atividade sobre o crescimento de bactérias Grampositivas e Gram-negativas, porém não foi eficaz para as cepas fúngicas. Todos os microrganismos que apresentaram CIM nas concentrações de 250, 1000 , e $2000 \mathrm{mg} / \mathrm{mL}$, obtiveram halos de inibição no teste de difusão em ágar,exceto $P$. mirabilis. Somente Bacillus cereus e Micrococcus luteus apresentaram CMM de 1000 e $2000 \mathrm{mg} / \mathrm{mL}$, respectivamente. Isto poderia ser explicado pelo tipo de processo metabólico dos mesmos o que os levaria a apresentarem maior sensibilidade à ação do extrato nas concentrações propostas. Ademais, observa-se que houve diferença expressiva entre as duas bactérias, relacionada à CMM, provavelmente pelo fato de $B$. cereus ser um organismo formador de endósporo e aeróbio estrito e o Micrococcus ser fermentador facultativo e não formador de esporo. (Tabela 2).

Os resultados obtidos confirmaram estudo realizado por Silva e Filho (2002), no qual os extratos de $B$. forficata foram testados contra fungos filamentosos e leveduras patogênicas, por meio do teste de diluição em caldo, não havendo atividade antifúngica.

Kumar et al. (2005) verificaram a atividade antimicrobiana do extrato de Bauhinia racemosa, sendo este efetivo para Pseudomonas aeruginosa, Escherichia coli, Salmonella typhi, Shigella dysenteriae, Vibriocholerae, Staphylococcus aureus, Streptococcus pneumoniae, Micrococcusluteus, Staphylococcus epidermidise Candidaalbicans, em concentrações que variaram de 25 a $200 \mu \mathrm{g} / \mathrm{mL}$.

Ahmed et al (2012) avaliaram atividade antimicrobiana das espécies Bauhinia bowkeri, Bauhinia galpinii, Bauhinia petersianae Bauhinia variegata. Todas apresentaram boa atividade antimicrobiana, inibindo o crescimento de Staphylococcus aureus, Pseudomonas aeruginosa, Escherichia coli, Enterococcus faecalis, Aspergillus fumigatus, Candida albicans e Cryptococcus neoformans, nas concentrações de 30 a $2500 \mu \mathrm{g} /$ $\mathrm{mL}$.

Sousa et al. (2000) avaliaram a atividade antimicrobiana dos extratos das frações da $B$. forficata e $B$. microstachya por meio do método de difusão em ágar, observando que somente uma fração da $B$. forficata inibiu o crescimento de $E$. coli e $S$. aureus na concentração de $1000 \mu \mathrm{g} / \mathrm{mL}$.

Estes estudos corroboram com os resultados deste trabalho, demonstrando que não só $B$. forficata, mas várias espécies deste gênero possuem propriedades antimicrobianas. No entanto, há uma diferença entre as concentrações consideradas inibitórias. Isso pode ser explicado pela 
Tabela 2. Halos de inibição, Concentração Inibitória Mínima (CIM) e Concentração Microbicida Mínima (CMM) do extrato hidroalcoólico de $B$. forficata ante as cepas fúngicas e bacterianas.

\begin{tabular}{lccc}
\hline Microrganismos & $\begin{array}{c}\text { Halos de Inibição } \\
(\mathrm{mm})\end{array}$ & $\begin{array}{c}\text { CIM } \\
(\mathrm{mg} / \mathrm{mL})\end{array}$ & $\begin{array}{c}\text { CMM } \\
(\mathrm{mg} / \mathrm{mL})\end{array}$ \\
\hline Bactérias Gram-positivas & 17 & 250 & 1000 \\
Bacillus cereus(ATCC 11778) & 19 & 2000 & - \\
Bacillus subtilis(ATCC 6633) & 31 & 1000 & 2000 \\
Micrococcus luteus(ATCC 9341) & 24 & 2000 & - \\
Staphylococcus aureus (ATCC 6538) & 25 & 250 & - \\
Staphylococcus epidermidis (ATCC12226) & & & - \\
Bactérias Gram-negativas & - & - & - \\
Enterobactera erogenes(ATCC 13046) & 18 & - & - \\
Escherichia coli (ATCC 8739) & - & - & - \\
Klebsiella pneumoniae(ATCC 13883) & 16 & - & - \\
Proteus mirabilis (ATCC 25933) & - & 2000 & - \\
Pseudomonas aeruginosa(ATCC 25619) & 20 & & - \\
Salmonella typhimurium(ATCC 14028) & & - & - \\
Fungos & - & - & - \\
Candida albicans (ATCC 1023-1) & - & & - \\
Cryptococcus neoformans(ATCC 20509) & - & & - \\
Saccharomyces cerevisiae (ATCC 2601) & & & - \\
\hline
\end{tabular}

diferença de espécie, na qual cada uma apresenta composição química diferente e consequentemente maior ou menor concentração de princípios ativos, podendo haver ainda diferenças decorrentes do solo, clima e sazonalidade.

Os flavonoides, que são solubilizados em meio alcoólico, foram descritos como responsáveis pelas atividades biológicas de $B$. forficata (Silva e Filho, 2002), além de outros princípios ativos que sinergicamente contribuem para a atividade antimicrobiana.

As cepas Gram-positivas demonstraram-se mais sensíveis ao extrato do que as Gram-negativas. Isso se deve, provavelmente, a diferenças da composição química e física da parede celular entre os dois grupos de bactérias, entre outros fatores.

Tripanosomatídeos não patogênicos, como Herpetomonas samuelpessoai, surgiram como modelos importantes para o estudo dos processos biológicos básicos realizados por uma célula eucariótica (Gomes et al., 2012) sendo o mesmo utilizado como modelo para o estudo dos efeitos do extrato hidroalcóolico de $B$. forficata sobre o crescimento e diferenciação celular.
Os experimentos de crescimento celular em presença do extrato hidroalcoólico de Bauhinia forficata demonstraram que o número de tripanosomatídeos não foi reduzido e nem aumentado mesmo exacerbando-se a concentração do extrato, o que demonstra que este não inibe e nem estimula o crescimento de Herpetomonas samuelpessoai, nas concentrações testadas.

Com relação à diferenciação celular, não foram observadas formas diferenciadas (paraopistomastigota) estatisticamente significativas, quando comparadas com os sistemas controles (Tabela 4), indicando a ausência de substâncias contidas no extrato potencialmente mitogênicos e, ou, mutagênicos, nesse sistema experimental.

Não foi encontrado na literatura estudos dos efeitos de $B$. forficata sobre este flagelado, nem mesmo utilizando plantas do mesmo gênero. No entanto, estudos utilizaram este modelo experimental para avaliar os efeitos de diferentes plantas medicinais (Fernandes et al., 2011; Perazzo et al., 2011).

No que tange à determinação da $\mathrm{DL}_{50}$, após tratamento dos camundongos Swiss albinus, 
Tabela 3. Diferenciação celular de Herpetomonas samuelpessoai em meio quimicamente definido (ROITMAN et al., 1972), a $28^{\circ} \mathrm{C}$, por $72 \mathrm{~h}$, na presença e ausência do extrato hidroalcoólico de Bauhiniaforficata.

\begin{tabular}{cccc}
\hline $\begin{array}{c}\text { Concentração do extrato } \\
(\mathbf{m g} / \mathbf{m L})\end{array}$ & $\begin{array}{c}\text { Forma promastigota } \\
\%\end{array}$ & $\begin{array}{c}\text { Forma paramastigota } \\
\%\end{array}$ & $\begin{array}{c}\text { Forma opistomastigota } \\
\%\end{array}$ \\
\hline 0,0 & 87 & 9,5 & 3,83 \\
2000,0 & 73,8 & 19,8 & 6,7 \\
1000,0 & 93,17 & 6,83 & 0 \\
500,0 & 92 & 7,3 & 1,83 \\
250,0 & 93,7 & 4,2 & 2,8 \\
125,0 & 91,7 & 6,83 & 1,7 \\
62,5 & 95 & 4,7 & 1 \\
31,25 & 88,8 & 6,7 & 4,5 \\
15,625 & 79,8 & 13,5 & 6,5 \\
7,8 & 87 & 9,8 & 3,3 \\
3,9 & 85,2 & 13,8 & 1,3 \\
\hline
\end{tabular}

Tabela 4. Diferenciação celular de Herpetomonas samuelpessoai em meio quimicamente definido (ROITMAN et al., 1972), a $28^{\circ} \mathrm{C}$, por $72 \mathrm{~h}$, na presença e ausência do extrato hidroalcoólico de Bauhinia forficata.

\begin{tabular}{cccc}
\hline $\begin{array}{c}\text { Concentração do } \\
\text { extrato }(\mathbf{m g} / \mathbf{m L})\end{array}$ & $\begin{array}{c}\text { Forma } \\
\text { promastigota } \\
\%\end{array}$ & $\begin{array}{c}\text { Forma } \\
\text { paramastigota } \\
\%\end{array}$ & $\begin{array}{c}\text { Forma } \\
\text { opistomastigota } \\
\%\end{array}$ \\
\hline 0,0 & 87 & 9,5 & 3,83 \\
2000,0 & 73,8 & 19,8 & 6,7 \\
1000,0 & 93,17 & 6,83 & 0 \\
500,0 & 92 & 7,3 & 1,83 \\
250,0 & 93,7 & 4,2 & 2,8 \\
125,0 & 91,7 & 6,83 & 1,7 \\
62,5 & 95 & 4,7 & 1 \\
31,25 & 88,8 & 6,7 & 4,5 \\
15,625 & 79,8 & 13,5 & 6,5 \\
7,8 & 87 & 9,8 & 3,3 \\
3,9 & 85,2 & 13,8 & 1,3 \\
\hline
\end{tabular}

com concentrações de $1000 \mathrm{mg} / \mathrm{kg}, 1500 \mathrm{mg} / \mathrm{Kg}$ e $2000 \mathrm{mg} / \mathrm{kg}$ do extrato hidroalcoólico de B.forficata observação detalhada por um período de 14 dias, não foi constatado nenhum óbito, indicando que este extrato não apresenta toxicidade relativa para estes animais nas concentrações testadas.

O método do micronúcleo baseia-se na análise da frequência de danos ocorridos ao DNA, os quais são resultantes de mitoses ou meioses celulares que, em contato com agentes clastogênicos e aneugênicos, podem gerar a perda de fragmentos ou de cromossomos inteiros, formando assim os micronúcleos. A análise da relação entre eritrócitos policromáticos e normocromáticos fornece 0 indicativo do extrato estar diminuindo a produção de novos eritrócitos (policromáticos). Se isto ocorrer, a droga poderá ser considerada citotóxica (Fernandes et al., 2011).

Os dados da Tabela 5 demonstram os resultados do teste do micronúcleo obtidos em camundongos Swiss fêmeas e machos, tratados com as três doses do extrato de $B$. forficata $(1000,1500$ e $2000 \mathrm{mg} / \mathrm{Kg}$ ) e os controles positivo e negativo, nos tempos de 24 e 48 horas, respectivamente. São apresentados os números de eritrócitos policromáticos micronucleados (PCEMNs) para cada animal e a média de cada grupo. Esta Tabela também mostra a média da razão entre o número de eritrócitos policromáticos (PCE) e normocromáticos (NCE), em 2.000 células analisada/ animal.

Os resultados revelaram diferenças estatísticas significativas do número/índice percentual de PCEs micronucleados entre o grupo de animais do controle positivo (ENU $50 \mathrm{mg} /$ 
Tabela 5.Número de eritrócitos policromáticos (PCE) analisados, índice percentual de eritrócitos policromáticos micronucleados (PCEMNs) e razão de PCE/NCE observados em células provenientes da medula óssea de camundongos Swiss fêmeas e machos, após tratamentos (24 e 48 horas) com o extrato de B. forficata.

\begin{tabular}{|c|c|c|c|c|c|c|c|c|}
\hline \multirow{3}{*}{ Gupos Experimentais } & \multicolumn{2}{|c|}{ PCE analisados } & \multirow{2}{*}{\multicolumn{2}{|c|}{$\begin{array}{l}\text { PCEMN } \\
24 \mathrm{~h}\end{array}$}} & \multirow{2}{*}{\multicolumn{2}{|c|}{$\begin{array}{l}\text { PCEMN } \\
48 \mathrm{~h}\end{array}$}} & \multicolumn{2}{|c|}{ PCE/NCE } \\
\hline & $24 \mathrm{~h}$ & $48 \mathrm{~h}$ & & & & & $24 \mathrm{~h}$ & $48 \mathrm{~h}$ \\
\hline & (n) & (n) & (n) & $(\%)$ & (n) & $(\%)$ & & \\
\hline Controle $\mathrm{NaCl} 150 \mathrm{mM}$ macho & 6208 & 6260 & $28^{a}$ & $0,4500^{\mathrm{a}}$ & $35^{a}$ & $0,5600^{a}$ & 67,48 & 156,50 \\
\hline Controle $\mathrm{NaCl} 150$ mM fêmea & 6276 & 6281 & $27 a$ & $0,4300^{a}$ & $28^{a}$ & $0,4500^{a}$ & 261,50 & 330,58 \\
\hline Controle ENU 50 mg/Kg macho & 6057 & 5984 & $194^{b}$ & $3,2000^{\circ}$ & $109^{b}$ & $1,8200^{\mathrm{b}}$ & 1,04 & 0,96 \\
\hline Controle ENU 50 mg/Kg fêmea & 6034 & 6055 & $85^{b}$ & $1,4100^{b}$ & $101^{\mathrm{b}}$ & $1,6700^{b}$ & 1,17 & 3,47 \\
\hline B. forficata L. $1000 \mathrm{mg} / \mathrm{Kg}$ macho & 6266 & 6207 & $9 a$ & $0,1436^{a}$ & $6^{a}$ & $0,0967^{a}$ & 90,81 & 105,20 \\
\hline B. forficata L. $1000 \mathrm{mg} / \mathrm{Kg}$ fêmea & 6200 & 6227 & $1^{\text {a }}$ & $0,0161^{\text {a }}$ & $7^{a}$ & $0,1124^{a}$ & 119,23 & 127,08 \\
\hline B. forficata L. $1500 \mathrm{mg} / \mathrm{Kg}$ macho & 6209 & 6166 & $13^{a}$ & $0,2094 a$ & $9 a$ & 0,146 & 43,12 & 57,63 \\
\hline B. forficata L. $1500 \mathrm{mg} / \mathrm{Kg}$ fêmea & 6155 & 6096 & $4^{a}$ & $0,0650^{a}$ & $17^{a}$ & $0,2789^{a}$ & 80,99 & 80,21 \\
\hline B. forficata L. $2000 \mathrm{mg} / \mathrm{Kg}$ macho & 6186 & 6089 & $23^{a}$ & $0,3718^{a}$ & $12^{a}$ & $0,1971^{\text {a }}$ & 28,91 & 28,86 \\
\hline B. forficata L. $2000 \mathrm{mg} / \mathrm{Kg}$ fêmea & 6205 & 6181 & $16^{a}$ & $0,2579 \mathrm{a}$ & $24 a$ & $0,3883^{a}$ & 65,32 & 51,94 \\
\hline
\end{tabular}

$\mathrm{Kg}$ ) e controle negativo ( $\mathrm{NaCl} 0,9 \%$ ), bem como controle positivo e tratamentos $(1000-2000 \mathrm{mg} / \mathrm{Kg})$. Entretanto, essas diferenças não foram observadas entre o grupo de animais do controle negativo e o grupo de animais tratados com o extrato e, ainda, entre os sexos e os tempos de tratamento (24-48h), sugerindo que o extrato hidroalcoólico de folhas de B.forficata não apresenta potencial clastogênico e/ ou aneugênico. Este dado confirma os resultados encontrados no teste de diferenciação celular com $H$. samuelpessoai onde não foram constatadas células diferenciadas para opistomastigotas.

Estudo realizado por Macedo et al. (2008), utilizando folhas de Bauhinia monandra, por meio do teste do micronúcleo em Allium cepa (cebolas) e transformação plasmidial em Escherichia coli, comprovaram os resultados obtidos neste experimento, no qual o gênero Bauhinia não apresenta propriedades clastogênicas.

Menezes (2007) isolou dois flavonóides, quercetina-3,7-O-diramnosídeo e canferol-3,7-Odiramnosídeo do extrato aquoso de $B$. forficata. Os flavonóides, devido às suas propriedades antioxidantes e a capacidade de modular várias enzimas e receptores celulares, dependendo do número e posição dos grupos hidroxílicos no anel $A$ e $B$, podem agir como mutagênicos ou um próoxidante (Skibola e Smith, 2000; Silva et al., 2000; Hodek et al., 2002). Este fato pode estar relacionado com a ausência de mutagenicidade da $B$. forficata, no qual os grupos hidroxílicos podem estar em posições e em números não específicos para exercer ação mutagênica.

Conclui-se que o extrato hidroalcóolico apresenta atividade antimicrobiana e considerando as concentrações, tempo e sistemas testes avaliados, não é tóxico, nem apresenta clastogenicidade. Contudo, ensaios adicionais de mutagenicidade devem ser realizados para confirmar a hipótese de uso seguro da planta.

\section{REFERÊNCIA}

AHMED, S.J. et al. Study of comparison of antimicrobial potencies of Bauhinia Variegata leave extracts with antibiotics against selected bacteria. Journal of Pharmacy and Biological Sciences, v. 4, n. 3, p. 44-46, 2012.

BAUER, A.W. et al. Antibiotic susceptibility testing by a standardized single disc method. Amer. J. Clín. Path, v. 45, p. 493 - 496, 1966.

BARKVOLL, P., ROLLA, G. \& BELLAGAMBA, S. Interaction between chlorhexidine digluconate and sodium monofluorophosphate in vitro.Scand. Jour. of Dent. Research v.96 , n.1, p.30 - 33, 1988.

BARROS L.M, FIORINI J.E. Efeito da clorexidina e água ozonizada contra $S$. viridans na placa dentária bacteriana supragengival. Rev. Ass. Paul Cir. Dent, São Paulo,v.54, n. 1, p.47-52, 2000.

CECHINEL FILHO, V.; CAMPOS, F; CORREAA, RAspectos químicos e potencial terapêutico de imidas cíclicas: uma 
revisão da literatura. Quim. Nova, v.2, p. 230-241, 2003.

CURCIO, S.A. et al. Efeitos hipoglicemiantes de um extrato aquoso de Bauhinia forficata sobre as glândulas salivares de ratos diabéticos. Pak. J. Pharm. Sci. v. 25, n. 3, p. 493-9, 2012

DE SOUSA, E. et al.Hypoglycemic Effect and Antioxidant Potential of Kaempferol-3,7-O-( $\boldsymbol{\alpha}$ )-dirhamnoside from Bauhinia forficata Leaves. Journal of NaturalProduts, v. 67, p. 829-832, 2004.

FERNANDES, A.P. et al. Efeito do extrato hidroalcoólico de Pyrostegiavenusta na mutagênese "in vivo", e avaliação antimicrobiana, e interferência no crescimento e diferenciação celular "in vitro". Rev. Med. Minas Gerais, v.21, n.3, p. 267-274, 2011.

GOMES, M.D. et al. Efeitos da corrente elétrica sobre Herpetomonas samuelpessoai: um estudo ultra estrutural. Bioelectromagnetics., v. 33, p. 334$345,2012$.

Hodek P. et al.Flavonoids-potent and versatile biologicallyactive compounds interacting with cytochromes.Chemico-Biological Interactionsv.139, p. 1-21, 2002.

KUMAR et al. Antioxidant and antimicrobial activities of Bauhinia racemosaL. stem bark. Brazilian Journal of Medical and Biological Research, v. 38, p. 10151024, 2005.

KHALIL, N.M. PEPATOM. TandBRUNETTII. L. Free Radical Scavenging Profile and Myeloperoxidaselnhibition of Extracts from Antidiabetic Plants: Bauhinia forficata and Cissus sicyoides.Biol Res., v. 41, n. 2, p. 165-71, 2008.

LINO, C.S. et al. Atividade antidiabética da Bauhinia forficata extrai aloxano em ratos diabéticos. BiologicalPharmaceuticalBulletin, v. 27, p.125-127, 2004.

LUSA, M.G.; BONA, C. Análise morfoanatômica comparativa da folha de Bauhinia forficataLink e $B$. variegataLinn. (Leguminosae, Caesalpinioideae)Acta Bot. Bras., v. 23, n. 1, p. 196-211, 2009.

Macêdo MFS, Sisenando HAAACN, Queiroz JDF, Argolo ACC, Saturnino ACRD, Coelho LCBB, Batistuzzo-de-Medeiros SR. Determinar a genotoxicidade de uma infusão aquosa de Bauhinia monandra folhas. Rev. Bras Farmacogn 18: 509-516.2008.

MARQUES, G. S. et al. Avaliação de procedimentos para quantificação espectrofotométrica de flavonoides totais em folhas de Bauhinia forficata Link. Quím. Nova, v.35, n.3, p.517-522, 2012.

MATEUCA, R. et al. Chromosomal changes: induction, detection methods and applicability in human biomonitoring. Biochimie, v.88, n.11, p. 1515-31, 2006.

MENEZES, F.S.; MINTO, A.B.M.; RUELA,H.S.; KUSTER, R.M.; SHERIDAN,H.;FRANKISH,N.; . Hypoglycemic activity of two Brazilian Bauhinia species: Bauhinia forficata L. and Bauhinia monandra Kurz. Rev. Bras. Farmacogn, V.17, p. 8-13, 2007.
MINISTÉRIO DA SAÚDE. RENISUS - Relação Nacional de Plantas Medicinais de Interesse ao SUS. Espécies vegetais. Disponível em:http://portal.saude.gov.br/ portal/arquivos/pdf/RENISUS.pdf. 2009.Acesso em: 4 de abril de 2013.

NCCLS.Methods for diluition antimicrobial susceptibility tests for Bacteria That Grow aerobically, (6th ed.) NCCLS document M7-A6. NCCLS, 949 West Valley Road, Suite 1400,Wayne, PA: 19087-1898 USA, 2003.

OECD - ORGANIZATION FOR ECONOMIC COOPERATION AND DEVELOPMENT. Guidance document on the recognition, assessment, and use of clinical signs as humane endpoints for experimental animals used in safety evaluation, ENV/ JM/MONO(2000)7.

OLIVEIRA, C.Z. et al. Propriedades anticoagulantes e antifibrinogenolytic do extrato aquoso de Bauhinia forficata contra venenos de serpentes. J. Ethnopharmacol., v. 98, n. 1-2, p. 213-6, 2005.

PEROZA, L.R. et al. Bauhinia forficata impede movimentos de mastigação vazios induzidos por haloperidol em ratos e tem potencial antioxidante in vitro. Neurochem Res., v. 38, n. 4, p. 789-96, 2013.

PERAZZO, F.F et al. Gingko Bilobaleaves extract on growth and morphology of trypanosomatids. BolLat Caribe Plant Med Arom., v.10, n. 2, p. 147-54, 2011.

ROITMAN, et. al. Growth of an insect trypanosomaitid at $37^{\circ} \mathrm{C}$ in defined medium. Journal of Protozoology, v. 19, p. 346-349, 1972.

SCHMID, W. The micronucleus test for cytogenetic analysis. In: Hollaender, A. (Ed.). Chemical mutagens: principles and methods for their detection. New York: Plenum Press, p.31-53, 1976.

SILVA, K .L.; FILHO, V. C. Plantas do Gênero Bauhinia: Composição química e potencial farmacológico. Quim. Nova, v. 25, p.449, 2002.

SILVA, K. L. et al. Cechinel, V.; Phytochemical and pharmacognositcinvestigatíon of Bauhinia forficata Link (Leguminosae).Z. Naturforsch C, v. 55(5-6), p. 478-80, 2000.

SISENANDO, H.A. et al. Evaluation of the genotoxic potential of Bauhinia monandra leaf lectin (BmoLL). Food and Chemical Toxicology, v. 47, p. 303-308, 2009.

SKIBOLA, C.F.; SMITH, M.T. Potential health impacts of excessive flavonoid intake. Free Radical Biologyand Medicine, v. 29, n. 3- 4, p. 375-383, 2000.

SOUZA, R S. S.; Santos, D. R; BELLA CRUZ, R C.; VI Seminário Integrado de Iniciação Científica, Camboriú, Brasil, 2000.

TROJAN-RODRIGUES, M. et al. Plants used as antidiabetics in popular medicine in Rio Grande do Sul, southern Brazil. Journal of Ethnopharmacology, v. 139, p. 155-163, 2012.

VARANDA, E. A. Atividade mutagênica de plantas medicinais. Rev. Ciênc. Farm. Básica Apl., v. 27, n.1, p.1-7, 2006. 